\title{
Can Satellite-derived Chlorophyll Imagery Be Used to Trace Surface Dynamics in Coastal Zone? A Case Study in the Northwestern Mediterranean Sea
}

\author{
Philippe Forget ${ }^{1}$ and Gael André ${ }^{2}$ \\ ${ }^{1}$ LSEET, UMR 6017 CNRS-Université du Sud Toulon Var, BP132, 83957 La Garde, France, \\ E-mail: philippe.forget@1seet.univ-tln.fr \\ 2 IFREMER, DYNECO, Centre de Brest, BP70, 29280 Plouzané, France, \\ E-mail: Gael.Andre@ifremer.fr
}

Received: 3 May 2007 / Accepted:4 June 2007 / Published: 6 June 2007

\begin{abstract}
A comparison of chlorophyll data from SeaWiFS imagery and modeling results from a 3D hydrodynamical model was performed over the northwestern Mediterranean for the entire year of 2001. The study aims at investigating the information content brought by satellite-derived chlorophyll concentration ([Chl]) maps concerning surface dynamics in coastal zone. The study is mainly focused on the Gulf of Lions (GoL) and its outer region, which are mainly influenced by the Rhône River, local winds and the Northern Current (NC) flowing from the East along the continental slope. The physical hydrodynamical model was continuously run and 40 SeaWiFS images, presenting a significant coverage of the studied area, were selected. The comparison between [Chl] and sea surface salinity (SSS) fields on a pixel basis showed no definite correlation trends. Three reasons are given in discussion for that result. However, the comparison emphasized areas close to the coasts which were under the influence of different inputs not considered in the model and also of upwellings. A qualitative analysis of the data performed out of these regions exhibited significant similarities between [Chl] and SSS features. The signature of the Rhône ROFI (Region of Fresh Water Influence) and, in some cases, of the NC, was evidenced on [Chl] maps. We found that the intensity of this signature is seasonally modulated, e.g., it is low in open sea during the summer, oligotrophic, season. In addition, the signature of the Rhône ROFI in the western part of the GoL can be only partial due to local chlorophyll deficits. We conclude that, for the regional case studied, chlorophyll imagery can be used as a tracer of surface dynamics through surface salinity but with limitations, especially near the coasts.
\end{abstract}


Keywords: Gulf of Lions, SeaWiFS, surface chlorophyll, MARS hydrodynamical model

\section{Introduction}

Physical modeling is a modern tool to investigate the complex hydrodynamics of coastal zones. The specific complexity of coastal zones is mainly due to bathymetry, the coast line geometry, the river outflows and the wind field properties. Many models have been implemented in coastal zones of the world and sometimes several models have been used in a same coastal domain. In every case, validation of these models, which can differ considerably in terms of gridding, numerical methods, nesting, physical processes (such as turbulence, bottom friction, surface and inner stresses, rigid lid or free surface assumptions) is necessary. Validation is generally accomplished using in situ sensors such as scalar and vector current-meters, thermo-salinometers, bathythermograghs, drifters etc. Limitations of these devices are well known and the most severe one probably lies in the sampling rate of physical parameters, which is generally not sufficient regarding the high variability in time and space of these variables in coastal environment. That difficulty can be circumvented using assimilation methods. Another route to increase the number of measurements and, in particular, to extent the synopticity and time revisit scales that are required in coastal zone is remote sensing.

Remote sensing techniques have also their own limitations: only surface parameters -and a limited number of them- can be generally measured; sampling in time can be large (one to several days). However their ability of periodically mapping physical parameters over more or less extended areas is recognized of prime importance. The main remote sensing techniques used in coastal zone are temperature radiometers, as the Advanced Very High Resolution Radiometer (e.g., recently, [1,2] in the northwestern Mediterranean), HF (e.g. Coastal Ocean Dynamics Applications Radar, [3]) and VHF radars [4,5] for wave and surface current measurements, and ocean color radiometers operating in the visible. Two kinds of these latter can be distinguished:

- High-resolution radiometers as HRV (High Resolution Visible) and TM (Thematic Mapper) on SPOT and Landsat platforms, respectively. They can provide maps of surface turbidity in relation with processes such as river plume dynamics (e.g. [6] for the Rhône River plume) and resuspension. These data have been already used in physical modeling of, e.g., the Gulf of Lion [7-9].

- Multi-spectral radiometers as CZCS (Coastal Zone Color Scanner), SeaWiFS (Sea Wide Field-Of-View Sensor), MODIS (Moderate Resolution Imaging Spectroradiometer) and MERIS (Medium Resolution Imaging Spectrometer). These sensors have a lower spatial resolution than the previous ones at the benefit of a much larger extent of the observation zone and a one-day revisit period in cloudless conditions. They provide maps of biogeochemical constituents, mainly chlorophyll and, for some of these sensors, yellow substance and solid suspended matter.

This paper focuses on the second kind of sensors. It addresses the question of the tracability of surface physical properties from images of satellite-derived chlorophyll concentration ([Chl]) maps. These properties refer to salinity, temperature and circulation The studied area is the Gulf of Lions (GoL) in the northwestern Mediterranean. [Chl] maps were obtained from SeaWiFS and physical properties were computed using the model MARS-3D developed by Ifremer (Institut Français de Recherche pour l'Exploitation de la Mer). SeaWiFS images of chlorophyll have been often used these 
last years to study meso- to large-scale biogeochemical processes. Most of these studies were basically observational, the satellite data being generally merged with other satellite data and in situ data [10-13]. Studies where chlorophyll data are used in conjunction with an ocean model are scarcer. In these studies ocean color data have been envisaged in a diagnostic way, for example to validate 3 -D biogeochemical models $[14,15]$ or in a prognostic manner consisting in data assimilation into such models [16]. Our approach, which consists in comparing modeled dynamical properties to [Chl] map, is of the first kind.

The surface thermo-haline (salinity, temperature) and dynamical (currents) properties and SeaWiFS chlorophyll signatures of the GoL are compared for a prescribed year, 2001. The main physical features of the GoL are reviewed is section 2. Section 3 presents the physical numerical model, the SeaWiFS data and the methodology used to compare modeling and satellite data. The results of comparison are presented in section 4 and discussed in section 5.

\section{Physical properties of the GoL}

The main hydrodynamic features of the GoL are well known [17-19]. The dominant forcings in this area are strong continental winds, called Mistral and Tramontane, the Northern Current (NC) flowing along the shelf break from the Ligurian basin, north-east of the northwestern Mediterranean, to the Spanish coasts, and freshwater discharges, mainly from the Rhône River.

Mistral is a northerly wind channeled by the Rhône river valley and blowing in the northern part of the GoL. Tramontane is a northwesterly wind channeled between Pyrenees and Massif Central Mountains which blows in the western part of the gulf. Mixed Mistral and Tramontane wind systems occur in the majority of cases, resulting in inhomogeneous surface winds over the GoL (Figure 1). These winds exhibit a high temporal variability. They generally happen and die quite suddenly. Furthermore, they can show near the coasts a high spatial variability due to complex orographic effects. These winds generate well-known oceanographic features such as coastal rises to the surface of cold waters from the ocean depth, called upwellings, [20,21] and inertial currents [22]. Southeastern stormy winds constitute other winds that are commonly, but less frequently than Mistral and Tramontane, encountered in the GoL.

The NC is the main mesoscale circulation feature influencing the shelf circulation of the GoL [18]. The transport of this current vein, up to $300 \mathrm{~m}$ deep, ranges from 1 to 1.6 Sverdrup. The NC can intrude on the GoL at its eastern part. The interaction processes between the $\mathrm{NC}$ and the shelf circulation (including bathymetric effects) are responsible of mesoscale instabilities of the NC resulting in eddies and meanders [22, 23]. Mesoscale activity is found to increase from fall to winter and then displays a continuous decrease until summer [24].

The main fresh water input is brought by the Rhône River accounting for roughly $90 \%$ of the total fresh water inputs in the GoL. In its deltaic plain the Rhône River splits into two branches, the Grand Rhône and the Petit Rhône, distant by $50 \mathrm{~km}$. The Grand Rhône carries $90 \%$ of the total mean discharge, which is estimated to $1700 \mathrm{~m}^{3} \mathrm{~s}^{-1}$ (10\% for the Petit Rhône) [25]. The river discharge is highly variable over the year with peaks occurring in spring and fall.

This study mainly concerns the Region Of Freshwater Influence (ROFI, [26]) of the Rhône River, including Grand and Petit Rhône. The Rhône ROFI extends over the GoL and is composed of the primary plume and the dilution zone. The primary plume is that region connected to the estuary 
and which is dominated by momentum advection processes imparted by the freshwater buoyancy input. Generally, the extent of the Grand Rhône plume at sea is limited to 20-30 km [5]. The dilution zone can extend up to the Spanish coasts to the south and between Marseille and Toulon to the east.

Other fresh water outputs are located in the western part of the GoL. They consist of discharges mainly from rivers (Figure 2) but also from channels (e.g. canal du Midi) and lakes (e.g. Etang de Tau). The mean discharge of Aude and Hérault, which are the most important rivers flowing into the eastern part of the GoL, are 50 and $52 \mathrm{~m}^{3} \mathrm{~s}^{-1}$, respectively [27].

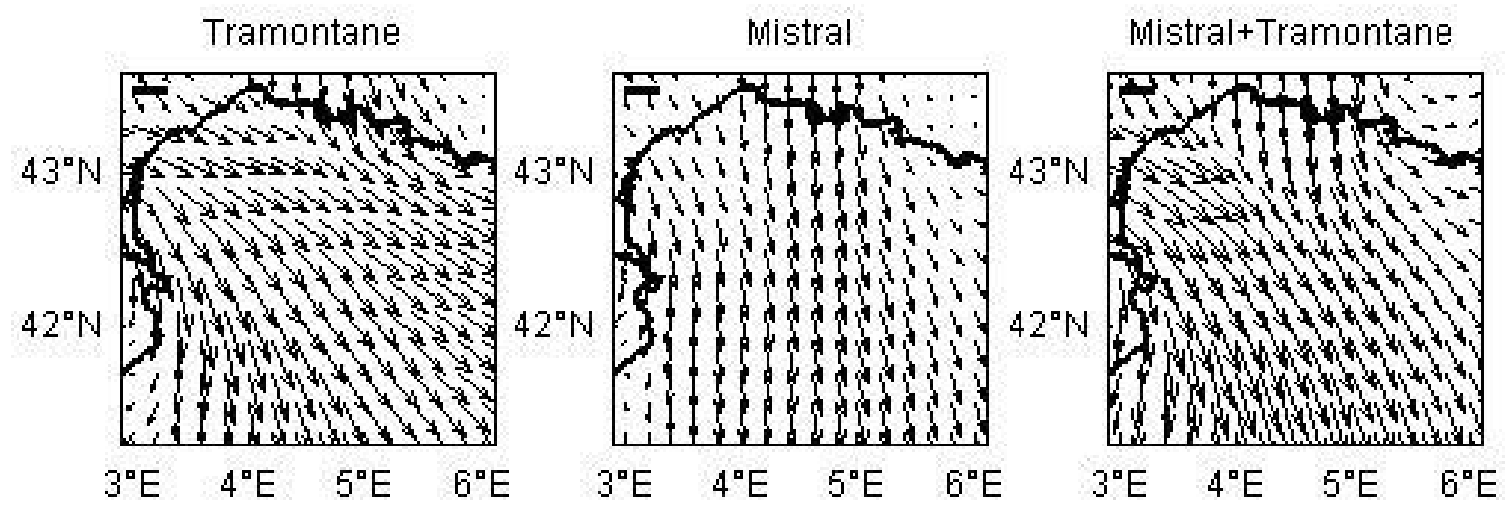

Figure 1. Three typical modeled wind fields over the GoL (model ALADIN of Météo France). They represent mixed situations of Mistral and Tramontane with, from left to right, dominant Tramontane, dominant Mistral and Tramontane and Mistral flowing with comparable intensies.

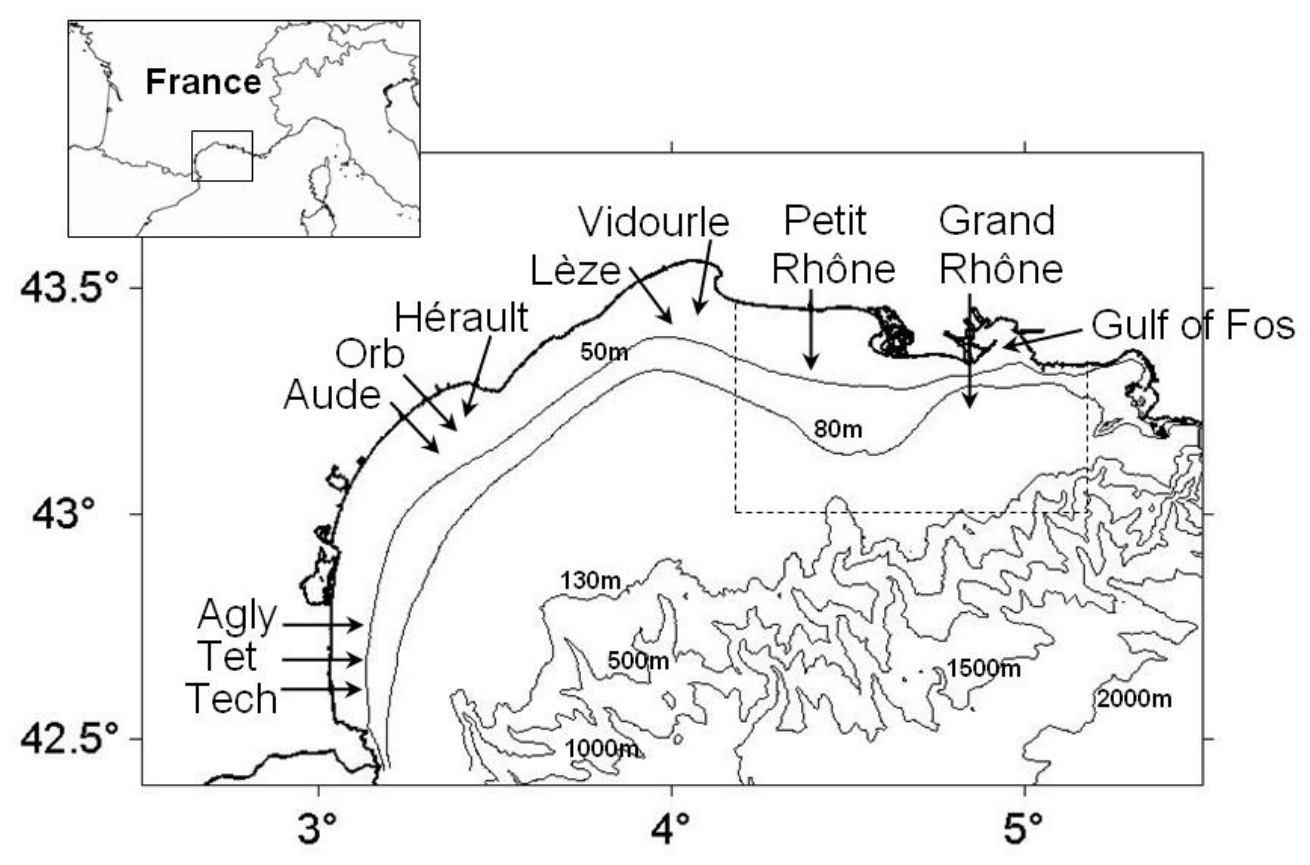

Figure 2. Rivers along the coasts of the GoL and bathymetry. The rectangle in dotted line is the Rhône region considered in Figure 6. 


\section{Material and methods}

\subsection{The physical numerical model}

The GoL dynamics is mainly driven by local forcings such as wind and river discharge, but it is also dependent on the background general circulation of the northwestern Mediterranean and in particular on the NC. A nesting technique was adopted to simultaneously take into account offshore and mesoscale processes. The computational code used here to simulate the circulation in the GoL is the MARS-3D (3 Dimensional Hydrodynamical Model for Applications at Regional Scale) model developed at Ifremer. The overall ability of the model to reproduce the hydrodynamics of the northwestern Mediterranean and especially of the GoL was demonstrated in a previous study by comparing modeled sea surface temperature (SST) and AVHRR satellite temperature measurements [23].

This model use an original semi-implicit and iterative time-step scheme allowing the simultaneous integration of internal and external modes on long time runs in a fast and conservative way. The main hypotheses are: free surface, Boussinesq approximation, hydrostatic equilibrium and incompressibility. Equations are discretized in finite differences on a staggered C-grid following Arakawa and Lamb's scheme [28]. A sigma-coordinate vertical transformation is used with refinements near the surface and the bottom. The vertical turbulent diffusions of momentum, heat and salt are computed using an algebraic relationship involving a Richardson number dependency [29]. The horizontal viscosity coefficient is of Laplace type and is computed following Smagorinsky's method subjected to lower and upper limits [30]. A particular attention was paid to compute momentum, salt and heat advections. We used for that TVD (total variation diminishing [31]) or Quick [32] schemes depending on the smoothness of the advected fields.

A chain of three nested MARS-3D models have been implemented with spatial resolutions increasing by a factor 3 at each embedding. The different embedding regions are given in [23]. The highest resolution model, NORMED, simulates the northern basin circulation, which extents from Spain to Italy and covers the area to the north of the Balearic Islands, on a $1.2 \mathrm{~km}$ horizontal grid resolution and with 30 vertical sigma levels. In this study NORMED was initialized on October 15, 2000, from coarser grid model outputs. At the southern open boundary of NORMED defined by latitude $39^{\circ} \mathrm{N}$, density fields (i.e. salinity and temperature) are prescribed at the open boundary using an upstream condition, implies that the external fields are advected into the simulated domain under inflow conditions. Surface elevation is prescribed and, to allow the radiation of perturbations, a contribution of the prognostic interior solution is added according to the flow relaxation scheme in $[33,34]$. Moreover, a sponge layer with an exponential increase of the momentum viscosity coefficients is applied along the open boundary.

Freshwater inputs from the Rhône River were only considered. We used daily river flow values provided by a measurement station located at Beaucaire, upstream of the Grand Rhône-Petit Rhône separation. The Petit Rhône flow was taken equal to 1/10 of the Grand Rhône flow.

The accuracy of ocean-atmosphere exchanges is a crucial point of the modeling, especially in the GoL where wind and atmospheric forcings present a high variability. NORMED is driven by the atmospheric fluxes issued from the global atmospheric model ARPEGE and by the wind fields computed by ALADIN model (Météo France). These model results are coherent because ALADIN is 
nested in ARPEGE. Spatial and time resolutions of ARPEGE are $50 \mathrm{~km} / 6 \mathrm{~h}$, and $10 \mathrm{~km} / 3 \mathrm{~h}$ for the regional small-scale meteorological model ALADIN. Sea surface momentum and heat fluxes were calculated from the surface pressure, air temperature, relative humidity and wind velocity at $10 \mathrm{~m}$ height with the bulk formulae [35] using the modelled sea surface temperature, to take into account the turbulent structure of the lower part of atmosphere.

\subsection{SeaWiFS imagery data set and corresponding physical conditions}

SeaWiFS has collected ocean color data for oceanic biochemistry since September 1997. The chlorophyll data used in this study were provided by the Inland and Marine Waters Unit, Joint Research Center, Italy, which makes data available from 1997 on a daily basis. The overall of SeaWiFS data processing is given in [36]. Chlorophyll-a surface concentration values, [Chl], are computed using a bio-optical algorithm linking to a functional of the reflectance band ratio $\rho(490 \mathrm{~nm}) / \rho(555 \mathrm{~nm})$ similar to that of O'Reilly et al. [37]. $\rho$ values are computed from the normalized water leaving radiance values, themselves computed from the calibrated top-of-atmosphere radiances through an atmospheric correction process accounting for Rayleigh multiple-scattering, aerosol single scattering and Rayleigh-aerosol coupling. A turbid-water correction is included in this atmospheric correction scheme which is intended to work in coastal waters [38-40]. Marine products have already been assessed against in situ measurements in coastal waters of the Mediterranean [36,39].

The chlorophyll images used here are Level-3 products implying a re-mapping procedure applied to the data [36]. Maps are in equirectangular, plate carrée, projection. This is also the projection of the MARS-3D data. The final pixel size is $2 \mathrm{~km}$, each pixel value resulting from values of smaller pixels, typically those with viewing angles smaller than $43^{\circ}$. The local time of observation (which varies with the orbit and the pixel position along the swath) is approximately $12 \mathrm{~h}$ for the region considered.

For the year under study (2001) we considered those SeaWiFS images for which available [Chl] fields cover at least $65 \%$ of the region defined by $2.88^{\circ} \mathrm{W}-6.06^{\circ} \mathrm{W} ; 41.13^{\circ}-43.66^{\circ} \mathrm{N}$ which includes the $\mathrm{GoL}$ and the offshore surrounding environment. Forty images were selected representing only $10 \%$ of the year. Table 1 gives the dates of these images and the corresponding Rhône flow values provided by Compagnie Nationale du Rhône (Beaucaire measurement station) and typical wind conditions. The images appear to be irregularly distributed over the year (Figure 3). Eighty percent of them were acquired in spring and summer. They are associated in $70 \%$ of cases with northerly to westerly winds which are the most frequent in this region. Eastern-southern winds are other common winds in the GoL but the fact that they bring clouds over the northwestern Mediterranean explains that no satellite image representing these wind conditions was available in our data set. The river flow values corresponding to SeaWiFS images range from 722 to $6279 \mathrm{~m}^{3} \mathrm{~s}^{-1}$. The values are maximal in March then decrease to values that are, from July to December, generally lower than the annual mean Rhône discharge. 
Table 1. List of the SeaWiFS images considered and associated Rhône discharge value, $Q$, and typical wind speed, $W$, and wind sector (the sector from which the wind is blowing). The typical wind of an image is the wind of maximum velocity within a zone defined by $4^{\circ} \mathrm{W}-5^{\circ} \mathrm{W} ; 42.7^{\circ}-43.2^{\circ} \mathrm{N}$.

Abbreviations: N (North), S (South), W (West), E (East).

\begin{tabular}{|c|c|c|c|}
\hline $\begin{array}{c}\text { Date } \\
(2001)\end{array}$ & $\begin{array}{c}Q \\
\left(\mathrm{~m}^{3} \mathrm{~s}^{-1}\right)\end{array}$ & $\begin{array}{c}W \\
\left(\mathrm{~m} \mathrm{~s}^{-1}\right)\end{array}$ & $\begin{array}{c}\text { wind } \\
\text { sector }\end{array}$ \\
\hline $02 / 05$ & 2278 & 4 & $\mathrm{~W}$ \\
\hline $02 / 10$ & 2308 & 9 & $\mathrm{NNW}$ \\
\hline $02 / 23$ & 1357 & 11 & $\mathrm{NW}$ \\
\hline $03 / 14$ & 6279 & 9 & $\mathrm{NW}$ \\
\hline $03 / 27$ & 5288 & 5 & $\mathrm{WNW}$ \\
\hline $04 / 01$ & 3958 & 5 & $\mathrm{SE}$ \\
\hline $04 / 12$ & 3980 & 12 & $\mathrm{NW}$ \\
\hline $04 / 26$ & 2704 & 6 & $\mathrm{~W}$ \\
\hline $05 / 08$ & 3306 & 5 & $\mathrm{WNW}$ \\
\hline $05 / 12$ & 2586 & 2 & $\mathrm{SW}$ \\
\hline $05 / 15$ & 2160 & 4 & $\mathrm{WSW}$ \\
\hline $05 / 19$ & 3242 & 6 & $\mathrm{~N}$ \\
\hline $05 / 26$ & 2375 & 3 & $\mathrm{~N}$ \\
\hline $05 / 29$ & 2007 & 4 & $\mathrm{WSW}$ \\
\hline $05 / 31$ & 2034 & 10 & $\mathrm{NW}$ \\
\hline $06 / 04$ & 1656 & 8 & $\mathrm{NW}$ \\
\hline $06 / 07$ & 1726 & 6 & $\mathrm{~W}$ \\
\hline $06 / 14$ & 2093 & 4 & $\mathrm{WSW}$ \\
\hline $06 / 16$ & 2044 & 9 & $\mathrm{NW}$ \\
\hline $06 / 18$ & 2529 & 14 & $\mathrm{NW}$ \\
\hline
\end{tabular}

\begin{tabular}{|c|c|c|c|}
\hline \multicolumn{5}{|c|}{ (continued) } \\
\hline $06 / 21$ & 2210 & 5 & W \\
\hline $06 / 28$ & 1620 & 13 & NW \\
\hline $06 / 30$ & 1505 & 4 & WSW \\
\hline $07 / 02$ & 1218 & 3 & SSE \\
\hline $07 / 07$ & 1627 & 9 & WNW \\
\hline $07 / 11$ & 1339 & 8 & WNW \\
\hline $07 / 21$ & 1910 & 7 & W \\
\hline $07 / 25$ & 1365 & 2 & N \\
\hline $07 / 30$ & 997 & 7 & WNW \\
\hline $08 / 10$ & 1384 & 10 & NW \\
\hline $08 / 22$ & 1123 & 6 & W \\
\hline $08 / 24$ & 921 & 4 & WSW \\
\hline $09 / 02$ & 1017 & 7 & NNW \\
\hline $09 / 05$ & 1152 & 15 & NNW \\
\hline $09 / 07$ & 1148 & 13 & NW \\
\hline $09 / 12$ & 1096 & 8 & NW \\
\hline $09 / 26$ & 1556 & 8 & WNW \\
\hline $11 / 04$ & 884 & 3 & NNW \\
\hline $12 / 07$ & 1393 & 6 & NE \\
\hline $12 / 25$ & 722 & 8 & WNW \\
\hline
\end{tabular}

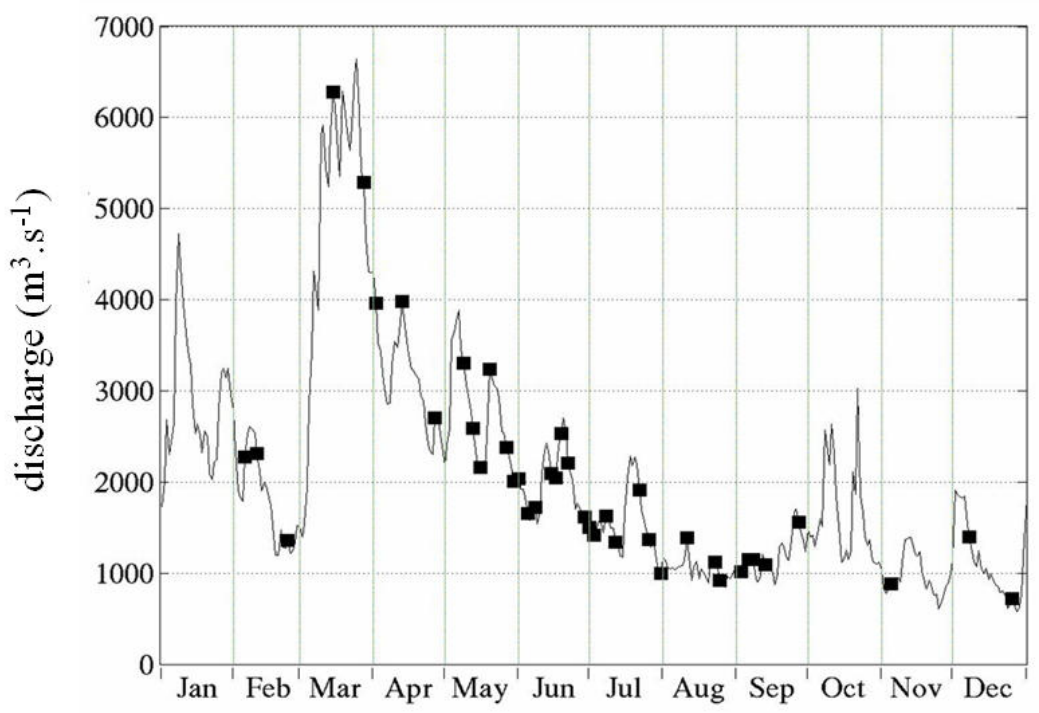

Figure 3. Daily Grand Rhône River discharge in 2001. Black boxes indicate the dates of the selected SeaWiFS images. 


\subsection{Methodology for the comparison of modeled surface fields and chlorophyll maps}

The methodology used to compare modeling results and satellite derived [Chl] measurements aims at answering the main question addressed by this study: can an image of chlorophyll, which is a biological parameter, as provided by water color sensors such as SeaWiFS over the extended GoL bring information on dynamical properties. The available chlorophyll data consist in several instantaneous images spanned, quite evenly, over the year considered. The MARS model was continuously run over the same year using modeled atmospheric forcings and large-scale circulation computational results. The selected model outputs are the surface fields of salinity, temperature and currents that are coincident with the available [Chl] maps over this year. In fact, SST fields will be considered only in the upwelling coastal zones. In particular, they cannot be used to characterize the Rhone river plume because no daily temperature measurement was available at the Rhône mouths (a rough model of river temperature varying sinusoidally over the year was just considered in the model). Moreover, the Rhône river temperature ranges from $9^{\circ} \mathrm{C}$ in winter to $24^{\circ} \mathrm{C}$ in summer, while the monthly average of the SST in the GoL ranges from $13^{\circ} \mathrm{C}$ to $22^{\circ} \mathrm{C}$. Hence the temperature differences between the Rhône river waters and the ambient seawater are generally small in such a way that SST is not a priori a sensitive tracer of the Rhône ROFI. However, it should noticed that signatures of the Rhône plume by satellite SST images have already been reported in literature (e.g., [41]). MARS and AVHRR SST fields were compared recently [23] but in open sea where surface temperature is only little influenced by fresh water inputs.

We first compare on a pixel basis [Chl] and sea surface salinity (SSS) fields, disregarding upwelling areas. We extract the different regions where both do not overlap and interpret the reason for that. Then chlorophyll images are qualitatively compared with the dynamical surface patterns expressed by modeled surface salinity and current fields.

Salinity and current values correspond to the mean values in the upper layer of the ocean. We considered a thickness of this layer, $\delta$, of the order of the penetration depth [42] associated to [Chl] measurements. However, this parameter, which varies with water turbidity and its possible vertical profile, was not known. We considered in a quite arbitrarily manner a layer depth $\delta=2 \mathrm{~m}$. Given the sigma-coordinate system of MARS, this needs to take the mean of model parameters over a varying number of upper layers, e.g. 1, 4 and 6 for a depth of $2500 \mathrm{~m}$ (deep ocean depth), $130 \mathrm{~m}$ (shelf break depth) and $60 \mathrm{~m}$ (mid-shelf depth), respectively. We verified that, in fact, the choice of the value of $\delta$ was not critical for the determination of mean salinity and current surface fields in the first 10 meters.

For illustration, twenty-four SeaWiFS images and the corresponding modeled surface salinity and current fields are shown among the 40 dates on Figure 4. The data are arranged chronologically. The reader is referred to Table 1 for river discharge and wind information.

Figure 4. Selected coincident maps of MARS surface salinity and current and SeaWiFS chlorophyll concentration. The horizontal bar in the upper left corner corresponds to a surface current of $1 \mathrm{~m} \mathrm{~s}^{-1}$. The white line draws the $130 \mathrm{~m}$ isobath which corresponds to the shelf break of the GoL. 

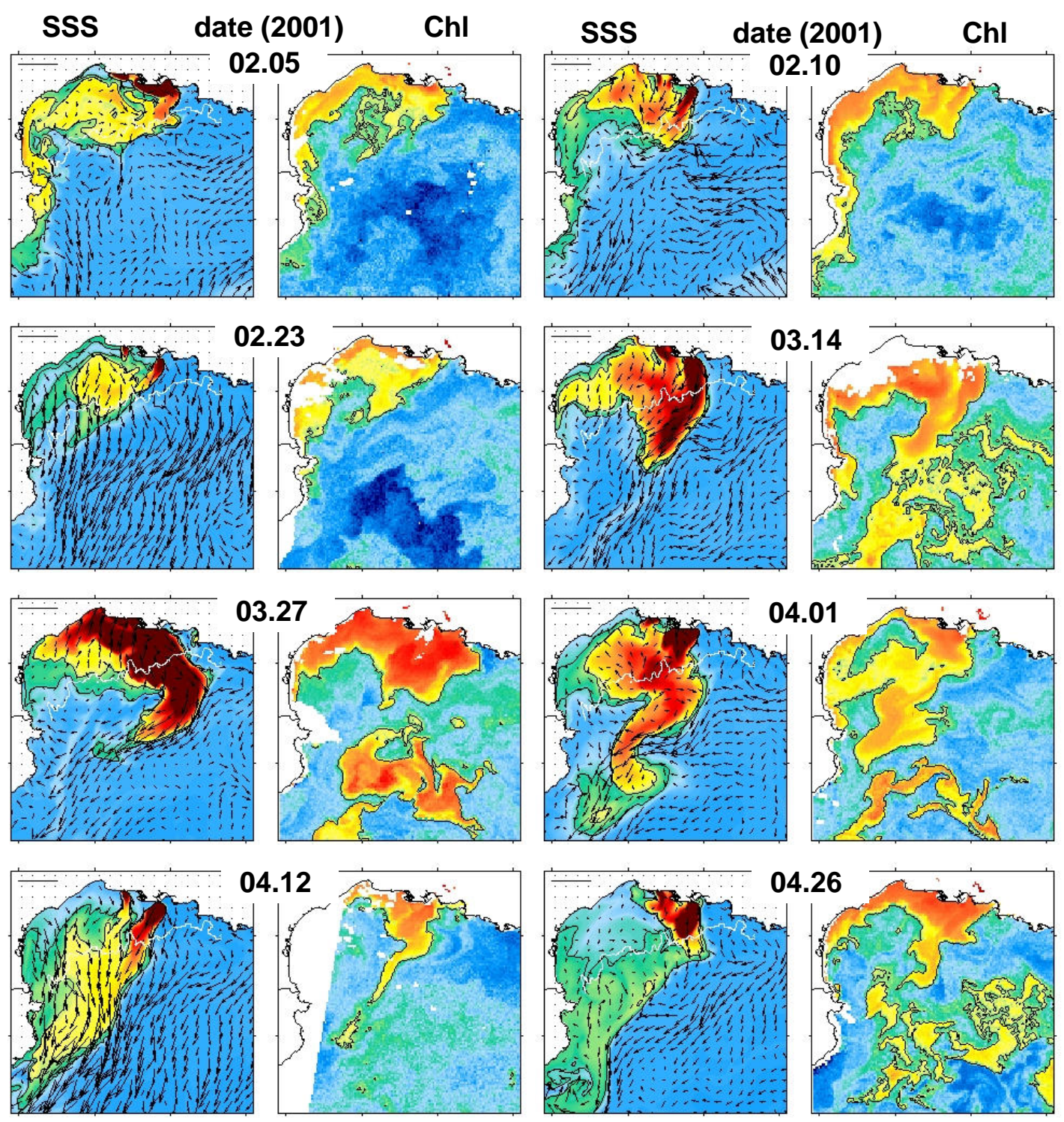

\subsection{2}
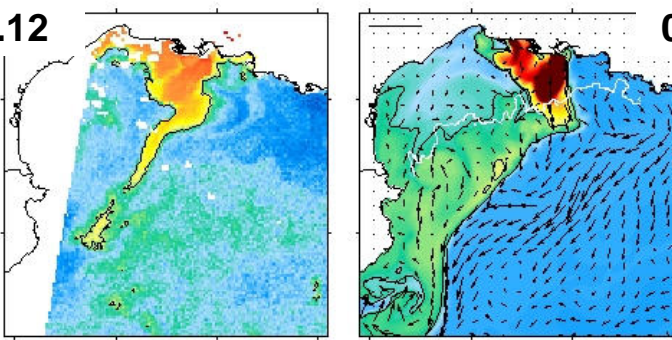

04.26

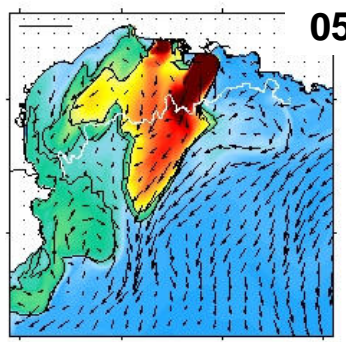

\subsection{8}
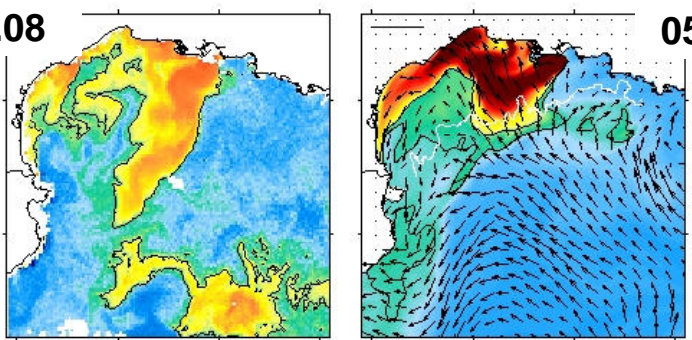

05.19
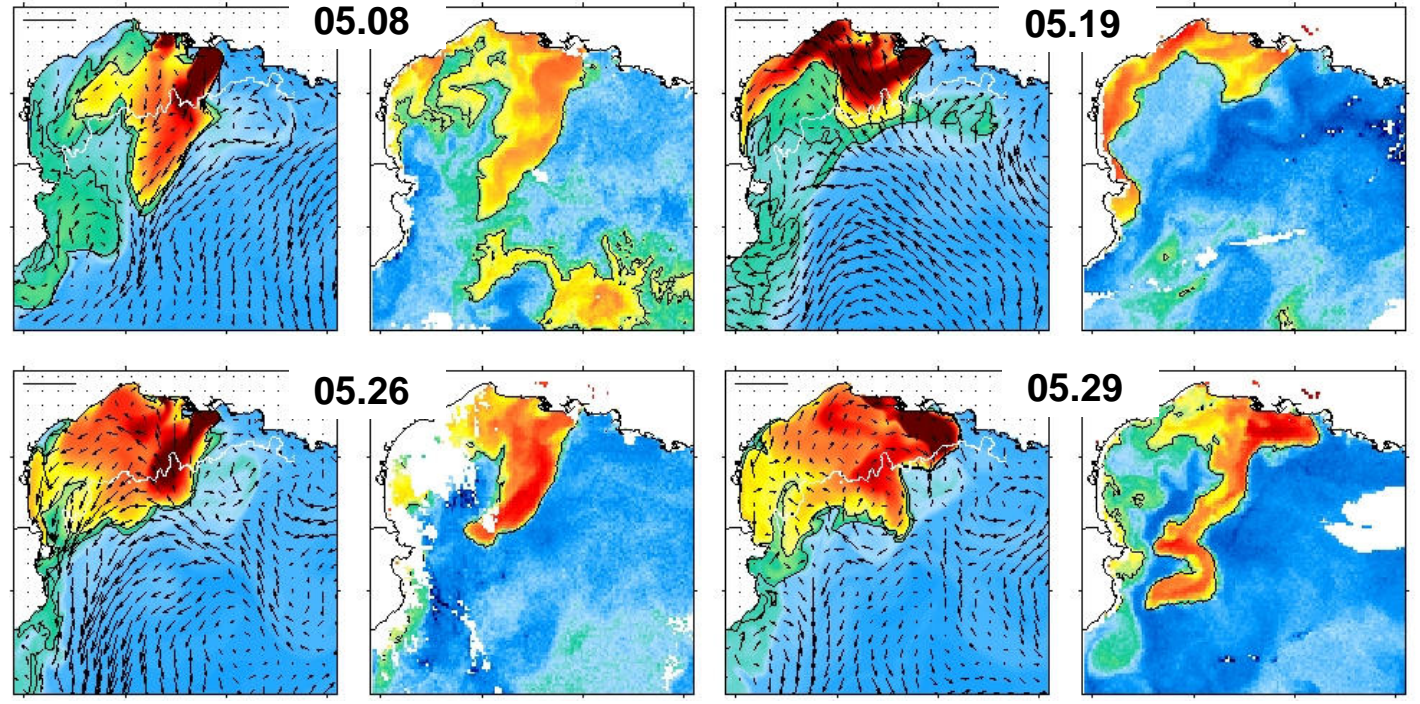

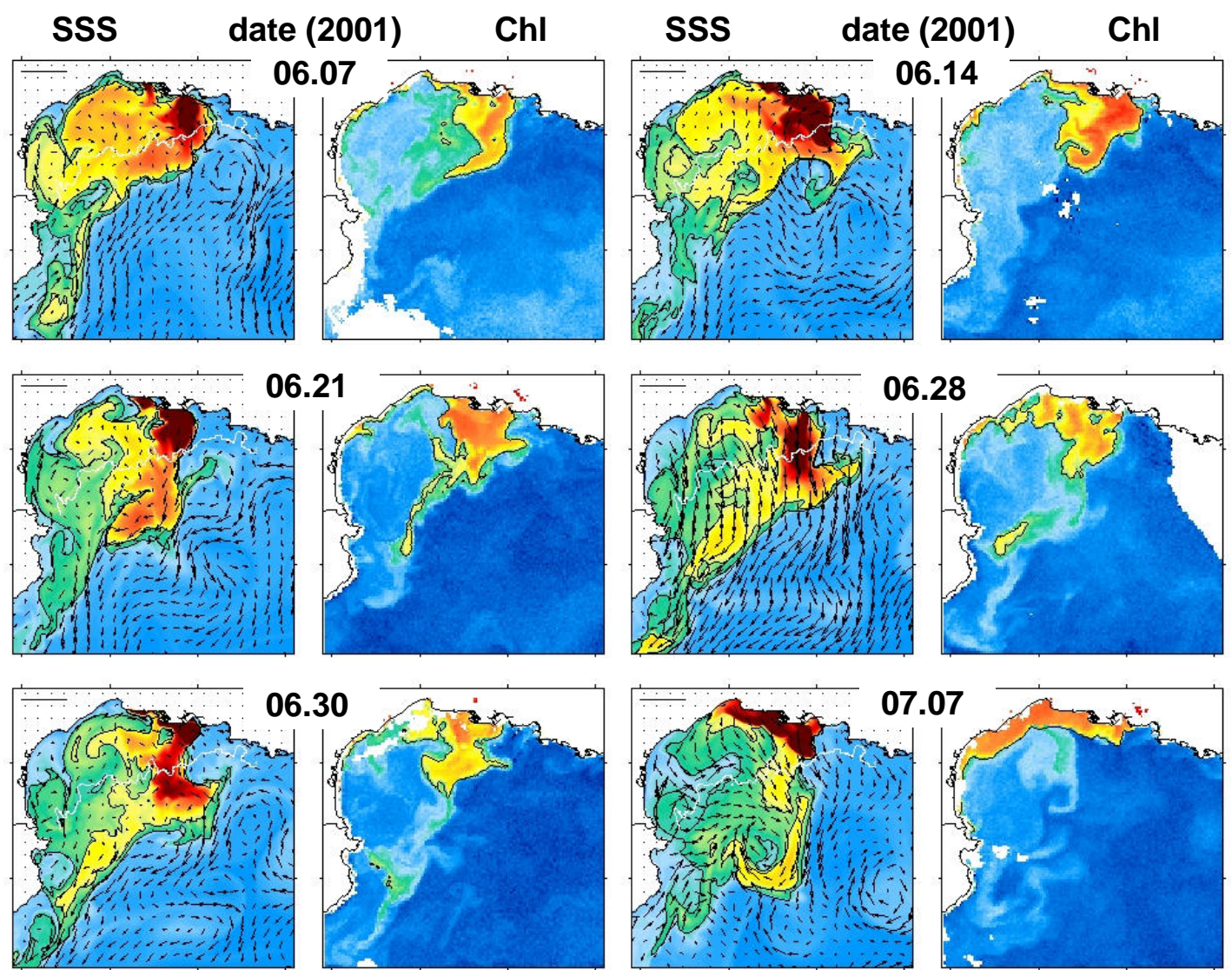

07.07
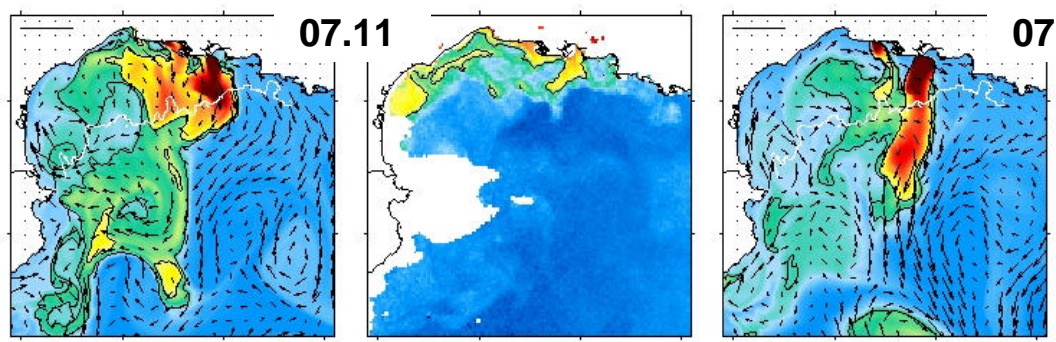

07.21

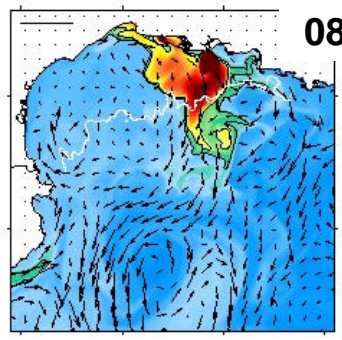

08.22
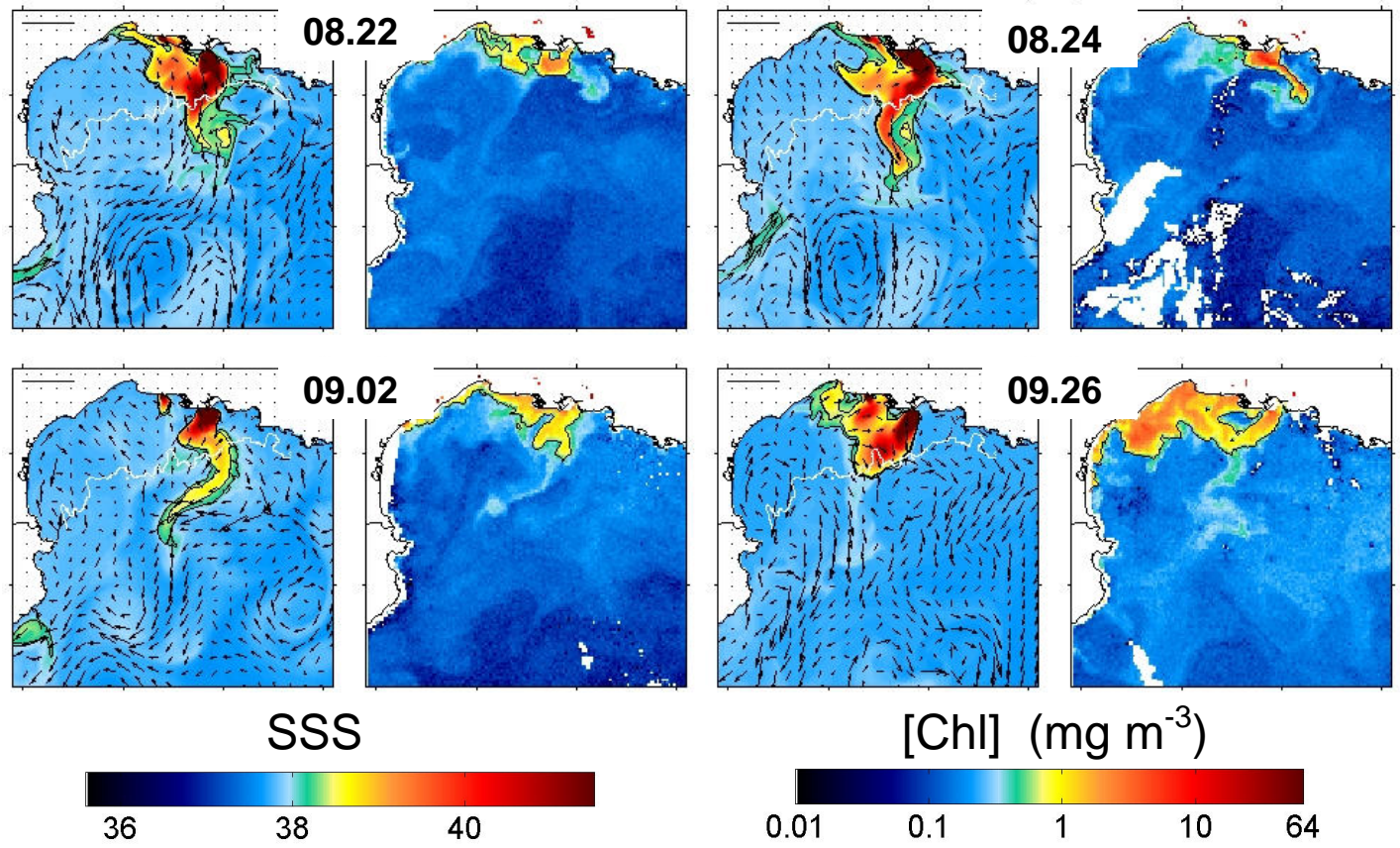

The same color scales are used for chlorophyll and salinity images. Whereas [Chl] logarithmic values are linearly distributed in logarithmic values over the color scale, SSS linear values are confined within the interval 35.6-41.5. This was done in order to enhance the color contrasts of salinity within 
that interval which appeared to give the best visual perception for comparison with chlorophyll images. In particular, SSS variations within that interval are well contrasted over a large part of the GoL, including the offshore region. Current vectors are given every $10 \mathrm{~km}$. Isocontours of $0.6 \mathrm{mg} \mathrm{m}^{-3}$ ([Chl]) and 37.5 and $37.8(\mathrm{SSS})$ are drawn on the images.

\section{Results}

\subsection{Quantitative comparison between chlorophyll and salinity maps}

SSS and [Chl] images are compared on a pixel basis. As the pixel size is different for model and satellite data, SSS values result from an averaging over the pixels for which the most part of the surface lie inside the satellite image pixel. The particular examples shown on Figure 5 reflect what is generally observed. The data scatter is very wide and no unique correlation exists, if any, between modeled SSS and [Chl] values. For example, no clear correlation is exhibited on February 5, some complex correlations are observed on April 26 and 3 correlation lines are present on May 19. We could identify the regions of the GoL associated with these 3 correlation lines for this particular case, for which SSS and [Chl] maps show obvious similarities (Figure 4), but such correlations are essentially not reproducible from one date to the other one.

Other attempts were made to find correlation trends between colocalized SSS and [Chl], by considering only specific regions as the vicinity of the Rhône estuary and the western part of the GoL (Figure 6), by thresholding the images and making the comparison only in the regions were SSS bins and [Chl] pixels overlap (typically: 37.8 upper threshold for SSS and $0.6 \mathrm{mg} \mathrm{m}^{-3}$ lower threshold for [Chl]). Also, comparisons were made by degrading model and satellite image resolutions up to $10 \mathrm{~km}$. These attempts were not conclusive.
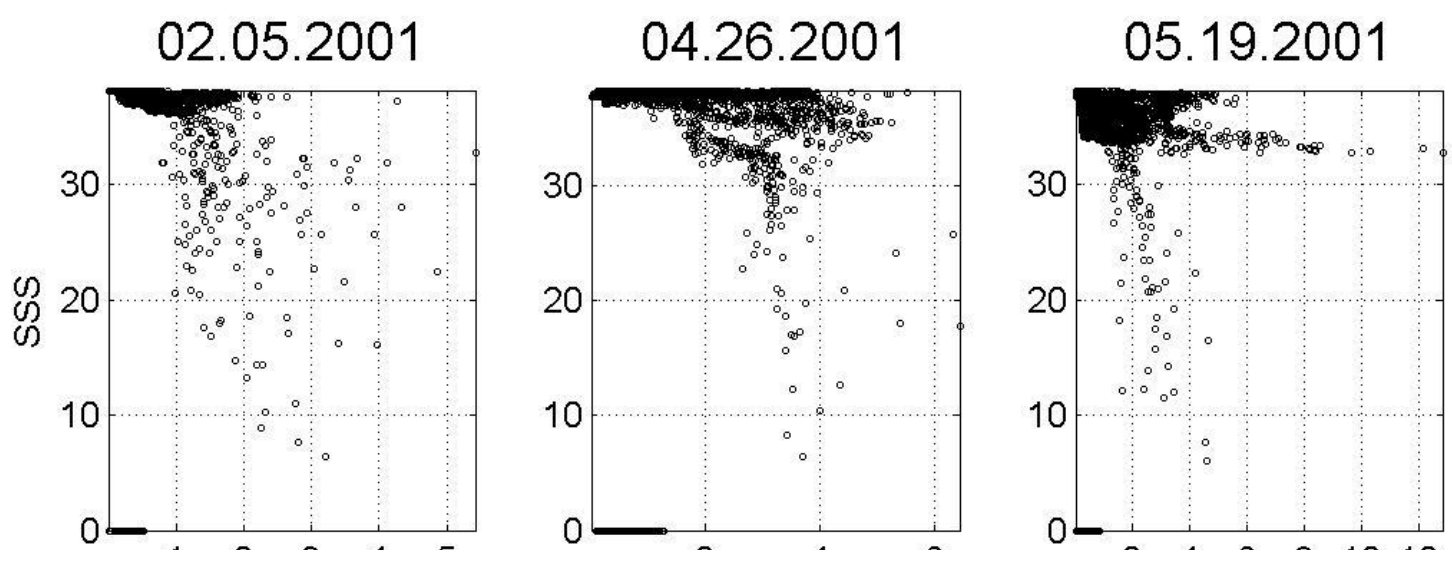

Figure 5. Comparison of MARS surface salinity and SeaWiFS chlorophyll at specific dates for the entire GoL. 

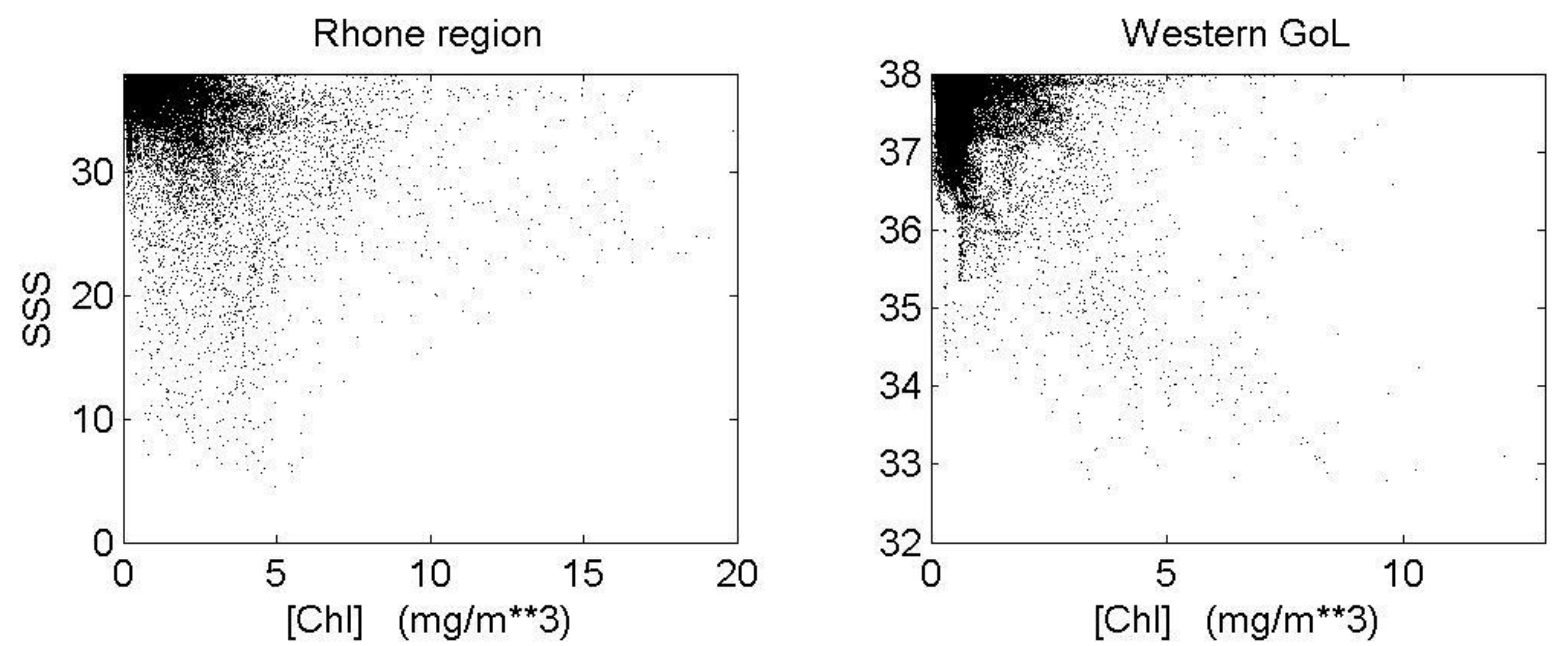

Figure 6. Comparison of MARS surface salinity and SeaWiFS chlorophyll over two limited regions in the GoL. The Rhône region is defined by $4.2^{\circ}-5.2^{\circ}$ in East longitude and $43^{\circ}-43.5^{\circ}$ in North latitude (see Figure 2) and the western GoL region by $3^{\circ}-4^{\circ}$ and $42.5^{\circ}-43^{\circ} 5$. All dates.

Nevertheless, using the methodology of comparison of [Chl] and SSS values on a pixel basis, some useful information could be brought by considering the statistics of the image pixels having relatively high [Chl] and SSS values $\left(>0.6 \mathrm{mg} \mathrm{m}^{-3}\right.$ and $>37.8$, respectively) (Figure 7a). The value of each pixel is equal to the number, $N$, of the images for which these conditions are satisfied. We prescribed a minimum value of $N$ of 5 . Then, white pixels are insignificant from a statistical point of view and/or correspond to waters which are under the Rhône influence and/or which are poor in chlorophyll pigments; and grey pixels correspond to locations where some biogeochemical activity exists quasi-independently of the Rhône influence (in terms of salinity). The analysis is focused here near the coast.

Five areas, termed A, B, C, D, E, could be highlighted. Their occurrence represents 65, 53, 29, 30 and $51 \%$, respectively, of the available data, i.e. of the amount of images that are, for each region, free of clouds. The existence of chlorophyll lenses in salty waters can be also observed outside regions A-E (along the south-western coastline as on February 23, and along the eastern coastline, as on March 27) but these cases are scarce.

Figure $7 \mathrm{~b}$ shows the statistics of the image pixels having relatively low $\mathrm{SST}\left(<\mathrm{SST}_{\text {mean }}\right.$ $-2^{\circ}$ where $\mathrm{SST}_{\text {mean }}$ is the mean SST value of the central part of the GoL $\left[4^{\circ} \mathrm{E}-5^{\circ} \mathrm{E} ; 42.25^{\circ} \mathrm{N}-42.75^{\circ} \mathrm{N}\right]$ ) and high SSS values (>37.8). As before, five regions could be highlighted which correspond quite well to areas A, B, C, D, E. A close examination of meteorological conditions shows that the lenses of cold and salty water on the figure are associated with wind-induced upwellings. The spatial distribution of these upwellings is in agreement with what has been already reported in literature [17] (Figure 8). 

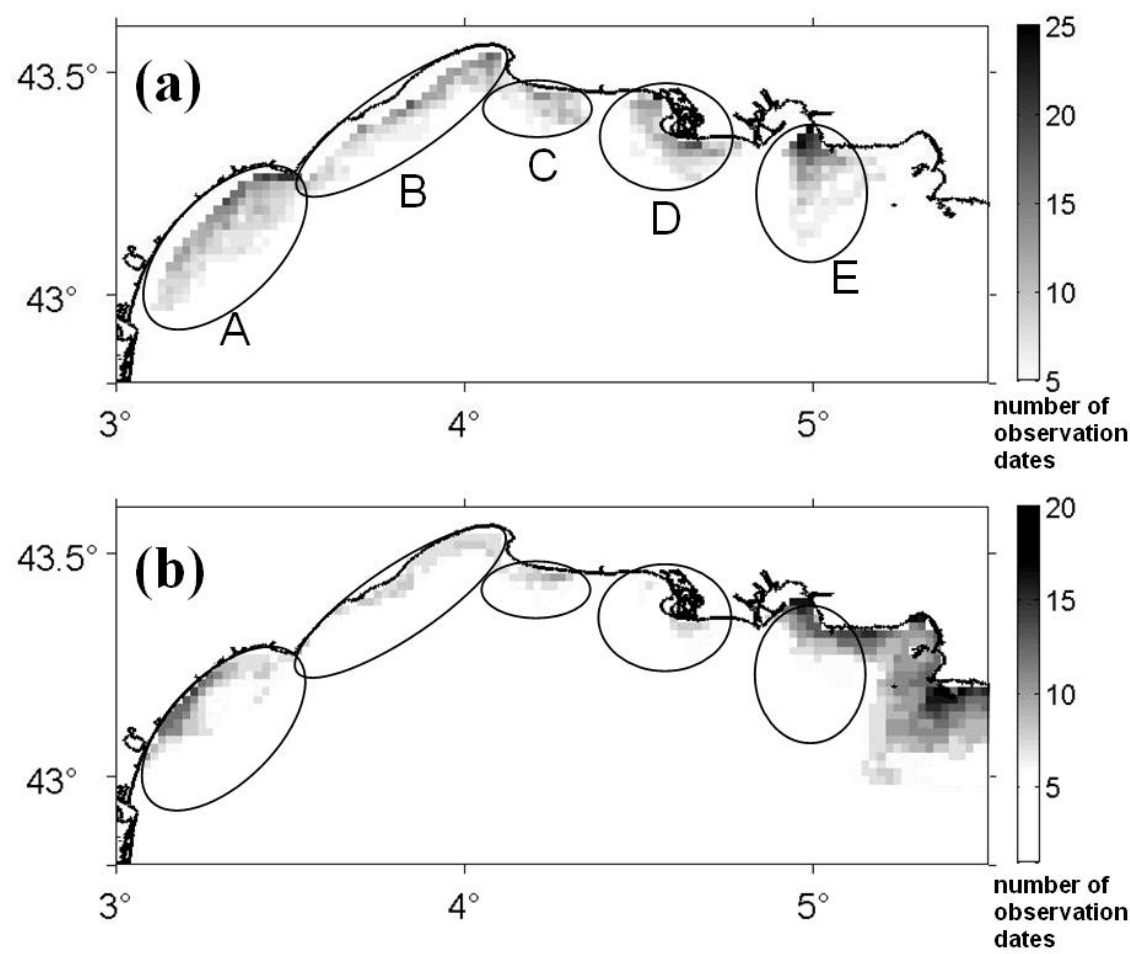

Figure 7. a) Number of observation dates satisfying [Chl] $>0.6 \mathrm{mg} \mathrm{m}^{-3}$ and SSS $>37.8$.

A minimum number of 5 is imposed. b) Number of observation dates satisfying SSS $>37.8$ and $\mathrm{SST}<\mathrm{SST}_{\text {mean }}-2^{\circ}$ where $\mathrm{SST}_{\text {mean }}$ is the mean SST in the central part of the GoL.

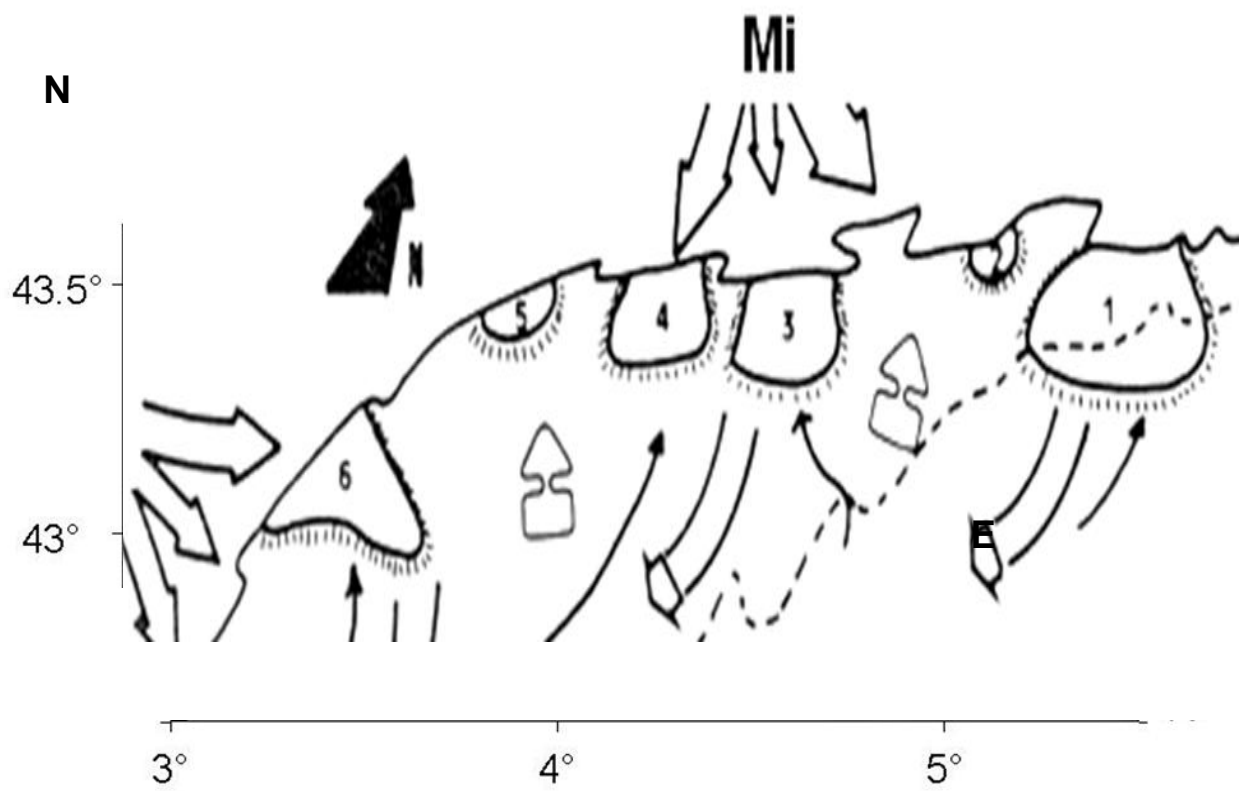

Figure 8. Schematic representation of Mistral- (Mi) and Tramontane- (Tr) induced phenomena in the GoL. 1-6 are upwelling zones. From Figure 2 of [17].

Then our observations tend to support an enhancement of marine productivity by upwelled waters, rich in nutrients, resulting in an increase of [Chl] concentrations. Both observations [43] and modeling results [44] have demonstrated the important role of upwellings on marine productivity in 
the GoL. However, there is not an exact correspondence between the upwelling events predicted by the model and the occurrence of regions A-D (defined by relatively high SSS and [Chl] values). For example, the percentages of occurrence reported here above are nearly the same if we consider high north-westerly winds ( $>9 \mathrm{~m} \mathrm{~s}^{-1}$ in Table 1$)$, which are favorable to upwelling events, and other wind regimes. Moreover, the zone of upwelling to the east of $5^{\circ} \mathrm{E}$ on modeled SST maps is not observed on [Chl] maps.

Regions A and B receive the influence of the rivers existing in this part of the GoL (Figure 2). In particular, the plumes of Hérault and Aude rivers are sometimes clearly distinguishable on [Chl] images (e.g. May 8 and June 14, respectively). Region B is influenced by two little rivers to the north but also by a large coastal pond (Etang de Tau) to which it is connected in the city of Sète $\left(43^{\circ} .42 \mathrm{~N}-3^{\circ} \cdot 68 \mathrm{E}\right)$. Region $\mathrm{E}$ is quite complex because it is located near or within the Rhône plume and because it comprises the Gulf of Fos (GoF), which is submitted to various freshwater river inputs [45]. In some cases, the visual comparison of [Chl] and SSS images in region E suggests some failure of the model to reproduce the extension to the east of the Rhône river plume (e.g., March 14 and 27, June 21). For the other cases, the comparison rather suggests an influence of the GoF on the chlorophyll content of the sea in this area, as on April 01 and August 24.

We conclude that the $[\mathrm{Chl}]$ patterns along the coasts of the GoL reflect not only dynamical processes but also biogeochemical processes due to the various coastal inputs that exist in the region.

\subsection{Qualitative comparison between modeled surface fields and chlorophyll maps}

We do not seek any more exact colocalizations of the structures nor relationships between chlorophyll and salinity. The regions termed A-E in section 4.1, where chlorophyll concentration can be affected by local upwellings and by local inputs, which are not included in the model, will not be considered.

The comparison exhibits four classes of cases:

- Class I: good overall agreement between [Chl] and SSS fields (42.5\% of the total number of observation dates). On Figure 4: February 5, 10, 23; March 14, 27; April 1; May 8, 19; July 21; September 2, 26. For these cases, surface waters of salinity lower than 37.5 generally correspond in shape and in area to waters of chlorophyll concentration greater than $0.6 \mathrm{mg} \mathrm{m}^{-3}$.

- Class II: good overall agreement as before but restricted to the eastern part of the GoL (32.5\% of cases). On Figure 4: April 12; May 26, 29; June 7, 14, 21, 28, 30.

- Class III: good overall agreements only near the Grand and/or Petit Rhône river mouths (17.5\% of cases). On Figure 4: July 7, 11; August 22, 24.

- Class IV: poor agreement (7.5\% of cases). On Figure 4: April 26.

From model results, the eastern-southern limits of the waters of low salinity often coincide with a horizontal shearing of the surface currents. Outside these dynamical (frontal) regions, we did not notice any clear correlation between chlorophyll patterns and local characteristics of the current field, especially within the lenses of low salinity water (e.g. Figure 4: February 23). Such an investigation was made using the vector maps at full resolution (and not on the under-sampled vector maps of Figure 4). This demonstrates that the chlorophyll content of a satellite image in the GoL refer to salinity rather than to surface dynamics. In other words, surface dynamics can be inferred from a [Chl] map but insofar as salinity features express these properties. It is not always the case and this is not 
surprising from a fundamental point of view since velocity and salinity are independent variables of the model.

Many examples in classes I and II show the influence of the NC on the eastern-southern boundaries of the low salinity-chlorophyllian region (e.g., Figure 4: May 26; June 7, 14, 21). The specific influence of the NC is less apparent in Mistral-Tramontane wind conditions because the offshore wind-induced circulation and the NC are more or less parallel (Figure 4: February 10, March 14, April 12, June 28). In the example of the Mistral event Figure 4: February 23, the eastern-southern limit of both SSS and [Chl] patches correspond to the wind-induced frontal boundary of the plume and is not directly related to the $\mathrm{NC}$ influence (the $\mathrm{NC}$ is flowing south of this zone).

The bloom episodes are interesting because for three of them (Figure 4: March 27, April 1, May 8) the eastern-southern limit of the low salinity-chlorophyllian region correspond to the NC influence in such a way that the NC vein appears as an oligotrophic vein separating two waters masses rich in chlorophyll. The relative oligotrophy of the NC is widely recognized (e.g. [46,43]. This effect is less marked on March 14 but that date corresponds to a Mistral event for which we can expect a horizontal mixing of the surface waters.

Class III cases correspond to the summer, oligotrophic period where [Chl] values are very low in the major part of the GoL. The summer period also corresponds to low river discharges resulting in a less extended dilution plume than in the first half of the year. In these conditions, the offshore [Chl] field is only weakly or very weakly contrasted. Relatively high [Chl] values can be found along the coasts where, apart from the cases reported for zones A-F, an overall good agreement with the shape of the plumes along the northern coastline is observed.

\section{Discussion}

Three reasons at least can explain the poor correlation between salinity and chlorophyll data that was found when comparing the images on a pixel basis.

First, there is a priori no unique relationship between salinity and chlorophyll concentration due to the diversity and complexity of the biological processes controlling the presence of chlorophyll pigments in the surface layer in the GoL. For example, no correlation was found between [Chl] and SSS values in upwelling coastal areas, which is not surprising since there, surface chlorophyll is mainly governed by locally upwelled nutrients than by the influence of the Rhône.

Furthermore, the biological activity is well known to vary with season and then we can expect a seasonal variability of the differences between chlorophyll and salinity surface values. This is especially evident on [Chl] images showing planktonic spring bloom manifestations: in these cases chlorophyll patterns can be observed in areas, south of the GoL, which are not reached by the Rhône waters. This is also clear on most of the [Chl] images acquired during summer and the beginning of autumn where the general oligotrophic conditions make chlorophyll contrasts weak in the offshore region.

Figure 9 illustrates the seasonal character of the surface chlorophyll content in the GoL. It shows the monthly means of [Chl] computed from SeaWiFS imagery over 4 years, here too provided by the Inland and Marine Waters Unit, Joint research Center. July to September statistically show very low concentrations in the major part of the GoL whereas they are maximum from March to May. 
These observations from SeaWiFS imagery on the seasonal chlorophyll variability are consistent with our knowledge of the biological activity in the northwestern Mediterranean [46].

Furthermore, we can expect that in the Rhône river plume and elsewhere where surface color is dominated by terrigenous matter and/or colored dissolved organic matter (yellow substance), SeaWiFS-derived [Chl] estimates are not safe. This question addresses the difficult problem of satellite data inversion in Case 2, coastal waters (e.g., recently, [47-49]. In addition, a possible source of uncertainty concerning satellite-derived [Chl] data lies in the possible effects of stratification (homogeneous layers are generally considered in bio-optical algorithms used in the inversion scheme of satellite data), especially -but not only- in the vicinity of the Rhône estuary. That question will not be addressed here despite its potential importance, as it was demonstrated by [50] concerning total suspended matter estimates from remote sensing techniques in stratified turbid waters in the Rhône and Elbe (Spain) plumes.

Lastly, it is accepted that no high resolution coastal model, even very efficient, can reproduce a physical situation which would correspond exactly to reality at the scale of a basin as the GoL, due to mesoscale circulation, wind forcing, physical assumptions of the model, etc. In particular, we can expect mislocalization effects biasing the comparison of colocalized salinity and chlorophyll fields. Such effects can be observed for patterns that are present, but not exactly at the same places, on both SSS and [Chl] maps e.g. on February 10 (Rhône plume), June 14 (pronounced eddy to the south of the Rhône estuary).

Apart for spring bloom events and chlorophyll structures associated with upwellings or coastal inputs, we observed that the shape of surface [Chl] and modeled SSS lenses, defined by isolines $0.6 \mathrm{mg} \mathrm{m}^{-3}$ and 37.5 respectively, often well resembled. This shows that a [Chl] satellite-derived map can be considered as a good tracer of the Rhône ROFI in terms of surface salinity and then can provide valuable information on important dynamical properties concerning, e.g., the shape of the primary Rhône plume, the extension of the Rhône ROFI, the influence of external forcings on the ROFI (outer currents, wind), eddy structures etc. But this conclusion must be nuanced.

Firstly, it was demonstrated that the signature of the Rhône ROFI on SeaWiFS images was modulated by the overall chlorophyll content of surface waters. So, chlorophyll images, in particular in summer, can underestimate the offshore ROFI extent.

Secondly, for the cases belonging to Class II, the ROFI is only partially marked in its eastern part whereas the western part shows a deficit of chlorophyll. This could be explained by a deficiency of the model to represent the dilution zone in this region. We think that, more likely, local conditions of oligotrophy prevent the detection of the ROFI in this area. Then Class II and Class III are similar and only differ by the spatial distribution of the phytoplanktonic activity over the GoL. 

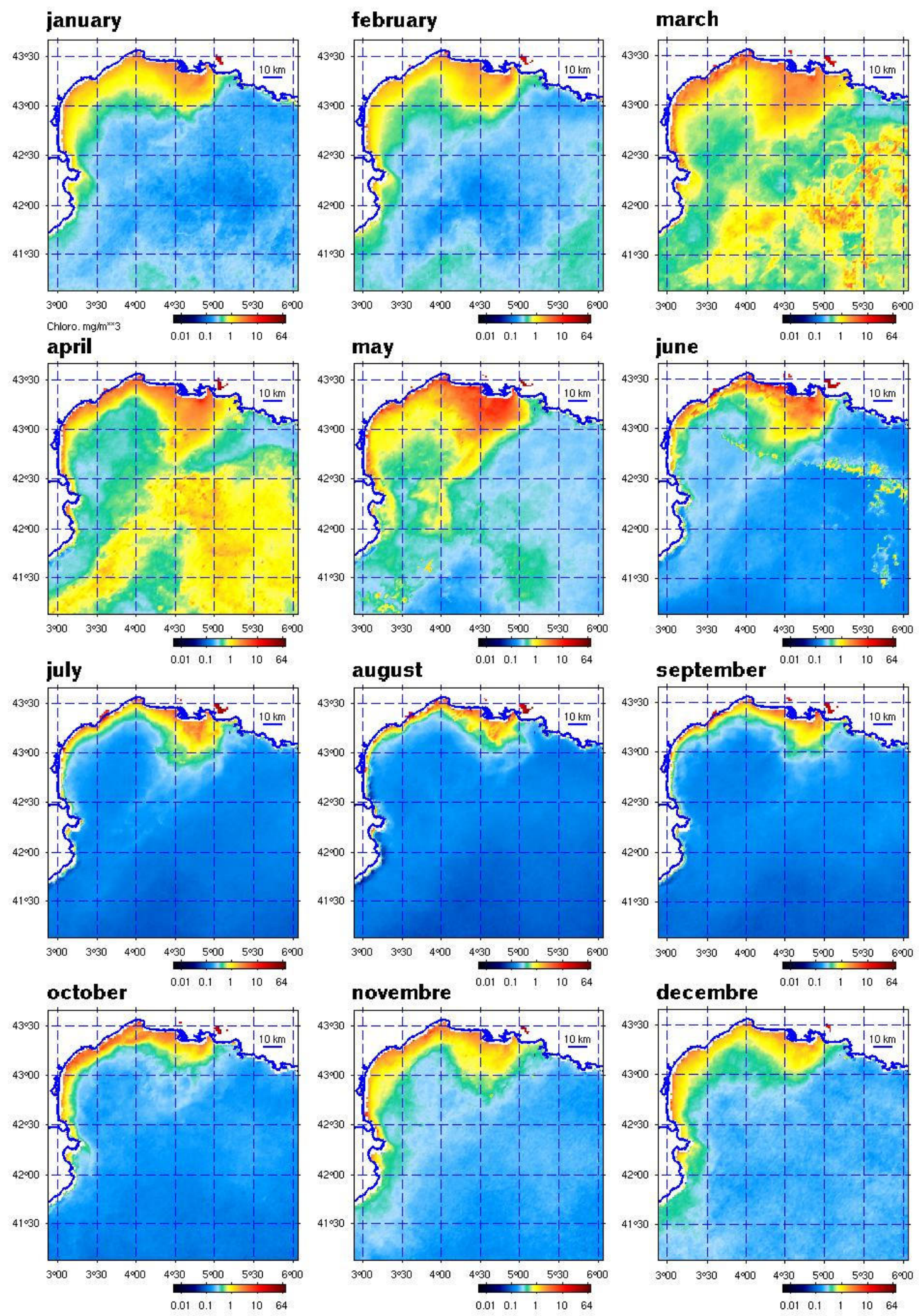

Figure 9. The mean monthly chlorophyll distribution in the GoL from SeaWiFS imagery for the period 1998-2001.

\section{Conclusions}

A comparative study of the chlorophyll spatial patterns at the ocean surface observed by SeaWiFS and the results of the hydrodynamical model MARS-3D was performed over the GoL for the 
year 2001. Forty dates, which corresponds to the availability of satellite images of good quality, were studied in detail. The comparison of colocalized [Chl] and SSS data showed that there was no definite, unique, relationship between these two quantities. However, examination and analysis of [Chl] and SSS images revealed significant morphological similarities between them, especially concerning the Rhone ROFI. Moreover, signatures of the NC were observed on [Chl] images. Also, lenses of enhanced chlorophyll were observed near the coasts, due to possible upwelling events but also to inputs of rivers, ponds and channels, not taken into account in the model, into the sea.

We conclude that water color imagery can be useful for investigating surface dynamics processes in the GoL but in a quite qualitative manner, in particular close to the coasts where biochemical processes can dominate. Furthermore, we observed a seasonal variability of the tracability of the ROFI by chlorophyll and, in some cases, a partial tracability due to local chlorophyll deficits in the western part of the GoL. This must be taken into account when interpreting chlorophyll maps in terms of surface dynamics.

\section{Acknowledgements}

This research was supported by Région Provence Alpes Côte d'Azur, Programme National d'Environnement Côtier (PNEC) and Programme Atmoshère et Océan à Moyenne Échelle (PATOM). The authors acknowledge the Institut du Développement des Ressources en Informatique Scientifique (IDRIS) which provided their high performance computing facilities. The authors are grateful to Philippe Fraunié and Pierre Garreau for their help.

\section{References}

1. Flexas, M.M.; Durrieu de Madron, X.; Garcia, M.A.; Canals, M.; Arnau, P. Flow variability in the Gulf of Lions during the MATER HFF experiment (March-May 1997). Journal of Marine Systems 2002, 33-34, 197-214.

2. Dufau-Juilland, C.; Marsaleix, P.; Petrenko, A.; Dekeyser, I. Three-dimensional modeling of the Gulf of Lion's hydrodynamics (northwest Mediterranean) during January 1999 (MOOGLI3 Experiment) and late winter 1999: Western Mediterranean Intermediate Water's (WIW's) formation and its cascading over the shelf break. Journal of Geophysical Research 2004, 109(C11), doi: 10.1029/2003JC002019.

3. Paduan, J.D.; Rosenfeld, L.K. Remotely sensed surface currents in Monterey Bay from shorebased HF radar (CODAR). Journal of Geophysical Research 1996, 101 (C9), 20669-20686.

4. Forget, P.; Devenon, J.L.; De Maistre, J.C.; Broche, P.; Leveau, M. VHF remote sensing for mapping river plume circulation. Geophysical Research Letters 1990, 17, 1097-1100.

5. Broche, P.; Devenon, J.L.; De Maistre J.C.; Forget, P. Experimental study of the Rhône river plume. Physics and dynamics. Oceanologica Acta 1998, 21(6), 725-738.

6. Forget, P.; Ouillon, S. Suspended matter off the Rhône river mouth from satellite imagery. Oceanologica Acta 1998, 21(6), 739-749.

7. Estournel, C.; Broche, P.; Marsaleix, P.; Devenon, J.L.; Auclair, F.; Vehil., R. The Rhone river plume in unsteady conditions: numerical and experiment results. Estuarine, Coastal and Shelf Science 2001, 53(1), 25-38. 
8. Durand, N.; Fiandrino, A.; Fraunié, P.; Ouillon, S.; Forget, P.; Naudin, J.J. Suspended sediment matter dispersion in the Ebro ROFI: an integrated approach. Continental Shelf Research 2002, 22(2), 267-284.

9. Reffray, G.; Fraunié, P.; Marsaleix, P. Secondary flows induced by wind forcing in the Rhône region of freshwater influence. Ocean Dynamics 2004, 54, 179-196.

10. Fratantoni, D.M.; Glickson, D. North Brazil current ring generation and evolution observed with SeaWiFS. Journal of Physical Oceanography 2002, 32, 1058-1073.

11. Ginzburg, A.I.; Kostianoy, A.G.; Krivosheya, V.G.; Nezlin, N.P.; Soloviev, D.M.; Stanichny, S.V.; Yakubenko, V.G. Mesoscale eddies and related processes in the northeastern Black Sea. Journal of Marine Systems 2002, 32(1-3), 71-90.

12. Hendiarti, N.; Siegel, H.; Ohde, T. Investigation of different processes in Indonesian waters using SeaWiFS data. Deep-Sea Research II 2004, 51(1-3), 85-97.

13. Stegmann, P.M.; Ullman, D.S. Variability in chlorophyll and sea surface temperature fronts in the Long Island Sound outflow region from satellite observations. Journal of Geophysical Research 2004, 109, C07S03, doi:10.1029/2003JC001984.

14. Huret, M.; Dadou, I.; Dumas, F.; Lazure, P.; Garçon, V. Coupling physical and biogeochemical processes in the Rio de la Plata plume. Continental Shelf Research 2005, 25(5-6), 629-653.

15. Le Fouest, V., Zakardjian, B., Saucier, F.J., Cizmeli, S.A. Application of SeaWiFS- and AVHRR-derived data for mesoscale and regional validation of a 3-D high-resolution physicalbiological model of the Gulf of St. Laurent (Canada). Journal of Marine Systems 2006, 60, 30-50.

16. Garcia-Gorriz, E.; Hoepffner, N.; Ouberdous, M. Assimilation of SeaWiFS data in a coupled physical-biological model of the Adriatic Sea. Journal of Marine Systems 2003, 40-41, 233-252.

17. Millot, C. The Gulf of Lions' hydrodynamics. Continental Shelf Research 1990, 10(9-11), 885-894.

18. Millot, C. Mesoscale and seasonal variabilities of the circulation in the Western Mediterranean. Dynamics of Atmospheres and Oceans 1991, 15, 179-214.

19. Millot, C. Circulation in the Western Mediterranean Sea. Journal of Marine Systems 1999, 20 (14), 423-442.

20. Hua, B.; Thomasset, F. A numerical study of the effects of coastline geometry on wind-induced upwelling in the Gulf of Lions. Journal of Physical Oceanography 1983, 13, 678-694.

21. Millot, C. Analysis of upwelling in the Gulf of Lions. In: J.C.J. Nihoul (Ed.), Hydrodynamics of Semi-enclosed Sea (pp. 143-154). Amsterdam: Elsevier, 1982.

22. Petrenko, A.A. Variability of circulation features in the Gulf of Lion NW Mediterranean Sea. Importance of inertial currents. Oceanologica Acta 2003, 26(4), 323-338.

23. André, G.; Garreau, P.; Garnier, V.; Fraunié, P. Modeled variability of the sea surface circulation in the western Mediterranean Sea and in the Gulf of Lions. Ocean Dynamics, 2005, 55, 294-308.

24. Alberola, C.; Millot, C.; Front, J. On the seasonal and mesoscale variabilities of the Northern Current during the PRIMO-0 experiment in the Western Mediterranean Sea. Oceanologica Acta 1995, $18(2), 163-192$. 
25. Ibanez, C.; Pont, D.; Prat, N. Characterization of the Ebre and Rhône estuaries: A basis for defining and classifying salt-wedge estuaries. Limnology and Oceanography 1997, 42(1), 89101.

26. Simpson, J.H. Physical processes in the ROFI regime. Journal of Marine Systems 1997, 12(1-4), 3-15.

27. Catalogue sédimentologique des côtes françaises. Côtes de la Méditerranée de la frontière espagnole à la frontière italienne. Paris: Editions Eyrolles, 1984.

28. Arakawa, A.; Lamb, V.R. Computational design of the basic dynamical processes of UCLA general circulation model. Methods in Computational Physics 1977, 17, 173-265.

29. Pacanovsky, R.C.; Philander, S.G.H. Parametrization of the vertical mixing in the numerical models of tropical oceans. Journal of Physical Oceanography, 1981, 11, 1443-1451.

30. Smagorinsky, J. General circulation experiments with the primitive equations, I. The basic experiment. Monthly Weather Review 1963, 91, 99-165.

31. Harten, A.. High resolution schemes for hyperbolic conservation laws. Journal of Computational Physics 1983, 49, 357-393.

32. Leonard, B.P. A stable and accurate convective modeling procedure based on quadratic upstream interpolation. Computer Methods in Applied Mechanics and Engineering 1979, 19, 59-98.

33. Martinsen, E.A.; Engedahl, H. Implementation and testing of a lateral boundary scheme as an open boundary condition in a barotropic ocean model. Coastal Engineering 1987, 11, 603-627.

34. Roed, L.P.; Cooper, C. A study of various open boundary conditions for wind-forced barotropic numerical ocean models. In Three-dimensional Models of Marine and Estuarine Dynamics, Nihoul J.C.J. and Jamart B.N. Eds, Elsevier (Amsterdam), 1987, 305-335.

35. Geernaert, G.L. Bulk parameterizations for the wind stress and heat fluxes. In: Geenaert and Plant, Editors, Surface Waves and Fluxes, Current Theory Vol. I, Kluwer Academic Publishers, 1990, p. 336.

36. Melin, F.; Bulgarelli, B.; Gobron, N.; Pinty, B.; Tacchi, R. An integrated tool for SeaWiFS operational processing. Report EUR19576EN, European Communities, 2000.

37. O'Reilly, J.E.; Maritorena, S.; Mitchel, B.G.; Siegel, D.A.; Carder, K.L.; Garver, S.A.; Kahru, M.; McClain, C. Ocean color chlorophyll algorithms for SeaWiFS. Journal of Geophysical Research 1998, 103(C11), 24937-24953.

38. Sturm, B.; Zibordi, G. SeaWiFS atmospheric correction by an approximate model and vicarious calibration. International Journal of Remote Sensing 2002, 23(3), 489-501.

39. Bulgarelli, B.; Melin, F.; Zibordi, G. SeaWiFS-derived products in the Baltic Sea: performance analysis of a simple atmospheric correction algorithm. Oceanologia 2003, 45(4), 655-677.

40. Melin, F.; Zibordi, G.; Berthon, J.F. Assessment of SeaWiFS atmospheric and marine products for the Northern Adriatic Sea. IEEE Transactions on Geoscience and Remote Sensing 2003, 41(3), 548-558.

41. Demarcq, H.; Wald, L. Surface dynamics of the Rhône plume inferred from infrared imagery. Oceanologica Acta 1984, 7 (2), 159-162.

42. Morel, A.; Berthon, J.F. Surface pigments, algal biomass profiles, and potential production of the euphotic layer: Relationships reinvestigated in view of remote-sensing applications. Limnology and Oceanography 1989, 34(8), 1545-1562. 
43. Conan, P.; Pujo-Pay, M.; Raimbault, P.; Leveau, P. Variabilité hydrologique et biologique du golfe du Lion. I. Transports en azote et productivité potentielle. Oceanologica Acta 1998, 21(6), 751-765.

44. Pinazo, C.; Marsaleix, P.; Millet, B.; Estournel, C.; Véhil, R. Spatial and temporal variability of phytoplankton biomass in upwelling areas of the Northwestern Mediterranean: a coupled physical and biogeochemical modelling approach. Journal of Marine Systems 1996, 7(2-4), 161191.

45. Ulses, C.; Grenz, C.; Marsaleix, P.; Schaaff, E.; Estournel, C.; Meulé, S.; Pinazo, C. Circulation in a semi enclosed bay under the influence of strong fresh water input. Journal of Marine Systems 2005, 56(1-2), 113-132.

46. Lefevre, D.; Minas, H.J.; Minas, M.; Robinson, C.; Williams, P.J. LeB.; Woodward, E.M.S. Review of gross community production, net community production and dark community respiration in the Gulf of Lions. Deep-Sea Research II 1997, 44(3-4), 801-832.

47. Li, R.R.; Kaufman, Y.J.; Gao, B.C.; Davis, C.O. Remote sensing of suspended sediments and shallow coastal waters. IEEE Transactions on Geoscience and Remote Sensing 2003, 41(3), 559566.

48. Warrick, J.A.; Mertes, L.A.K.; Siegel, D. A.; Mackenzie, C. Estimating suspended sediment concentrations in turbid coastal waters of the Santa Barbara Channel with SeaWiFS. International Journal of Remote Sensing 2004, 25(10), 1995-2002.

49. Wozniak, S.B.; Stramski, D. Modeling the optical properties of mineral particles suspended in seawater and their influence on ocean reflectance and chlorophyll estimation from remote sensing algorithms. Applied Optics 2004, 43(17), 3489-3503.

50. Forget, P.; Broche, P.; Naudin, J.J. Reflectance sensitivity to solid suspended sediment stratification in coastal water and inversion. Remote Sensing of Environment 2001, 77(1), 92103.

(C) 2007 by MDPI (http://www.mdpi.org). Reproduction is permitted for noncommercial purposes. 